\title{
Blood cast of the left bronchial tree caused by foreign body aspiration in a 12-year-old boy
}

\author{
Yu Liu ${ }^{1}$ and Jinbo Ning ${ }^{1}$ \\ ${ }^{1}$ Chongqing University
}

March 18, 2021

\begin{abstract}
This is a case report describing a rare condition.A 12-year-old boy had a blood cast of the left bronchial tree from bronchial hemorrhage caused by respiratory foreign body.He underwent rigid bronchoscopy and cast removal.
\end{abstract}

Title: Blood cast of the left bronchial tree caused by foreign body aspiration in a 12-year-old boy

Author names and affiliations :

Yu Liu, MD

165, Xincheng Road, Department of Pediatrics, Chongqing University Three Gorges Hospital, Wanzhou District, Chongqing, China.

Corresponding author: Jinbo Ning, MD

165, Xincheng Road, Department of Pediatric Surgery, Chongqing University Three Gorges Hospital, Wanzhou District, Chongqing, China.

Tel: 86-023-58103619

Email:popining@outlook.com

Study type: Case report

Manuscript: 883

Tables:0

Figures:5

Disclosure statement: No potential conflict of interest was reported by the authors.

Key words: Hemorrhage, foreign bodies, child, bronchoscopy

Blood cast of the left bronchial tree caused by foreign body aspiration in a 12-year-old boy

CASE: A 12-year-old boy was admitted to the PICU in Chongqing University Tree Gorges hospital after 2 days of persistent hemoptysis and exacerbation of respiratory hypoxia. This patient had a foreign body aspiration while consuming sunflower seeds. During an episode of violent coughing, several pieces of shell fragments were expectorated. Approximately after 10 minutes, the patient had a small volume of hemoptysis mixed with sputum that quickly turned into a bright red blood clot. Although the precise incidence of hemoptysis was not clear, the patient asserted it to be more than 10 times with a volume of more than $100 \mathrm{ml}$. 
Neither did the patient vomit blood, nor did he have abdominal pain, hematochezia, or melena. Though the patient was given aminomethylbenzoic acid and hemocoagulase in community medical institutions, the hemoptysis persisted. The patient was eventually transferred to our tertiary medical institution because of worsening respiratory distress and hypoxia. An immediate computed tomography (CT) scan of his chest revealed blockage of the left bronchus and its branches, emphysema in the left lower lobe, and exudative lesions in the left upper and lower lobe (Figure 1A, 1B). An immediate rigid bronchoscopy was performed under general anesthesia, and two blood casts were removed respectively from the left main bronchus/the upper lobe bronchial tree and the lower lobe bronchial tree (Figure 2). The inspection also showed that there was a $5 \mathrm{~mm}$ mucosal laceration on the left wall of the left bronchus at the level of carina without active bleeding. There was no further treatment of the laceration during the bronchoscopy. After a rigid bronchoscopy, the patient received regular intravenous antibiotics and hemostatic agents. The CT scan performed on the patient on the fourth day after cast removal showed that his trachea and bronchi were unobstructed, and the exudative lesions were significantly absorbed than before (Figure 3A, 3B). The patient was discharged and affirmed not feeling any discomfort. Throughout the 6-month outpatient follow-up after discharge from the hospital, the patient did not report the reappearance of hemoptysis.

DISCUSSION: A series of cases of bronchial cast formation have been reported in the last decades. ${ }^{1-7}$ Most cases were found in plastic bronchitis associated with congenital heart disease with Fontan physiology, pulmonary lymphatic anomalies, different types of infections and other conditions, ${ }^{8 ; 9}$ and the others were blood bronchial cast caused by bleeding associated with underlying lung lesions or coagulopathy. ${ }^{10-12}$ Blood bronchial cast in adults, especially the elderly, is predominantly associated with the hemoptysis caused by underlying lung diseases, such as bronchiectasis, tuberculosis, and lung cancer. Hitherto, massive hemoptysis in children is rare. The case we introduced here had a history of sunflower seed shell fragments aspiration. The bronchoscopy also detected a laceration in the bronchial mucosa enabling us to deduce that a foreign body scratched the bronchial wall and caused the bleeding. Bronchial foreign bodies are more common during childhood, especially in younger children. In some countries, peanuts, sunflower seeds, walnuts, and pistachios are the most typical snacks, which are also the most common respiratory foreign bodies found in bronchoscopy. ${ }^{13}$ This case suggested the plausibility of bronchial foreign bodies causing blood bronchial cast,notwithstanding the fact that similar cases have not been reported to the best of our knowledge.

\section{References}

1. Zhang X, Vinturache A, Ding G. 2019. Plastic bronchitis in a 3-year-old boy. CMAJ : Canadian Medical Association journal = journal de l'Association medicale canadienne. 191(48):E1336.

2. Li Y, Williams RJ, Dombrowski ND, Watters K, Daly KP, Irace AL, Visner GA, Rahbar R, FynnThompson F. 2020. Current evaluation and management of plastic bronchitis in the pediatric population. International journal of pediatric otorhinolaryngology. 130:109799.

3. Isobe M, Sasaki S, Hojo M, Emura S, Hoshina J, Kojima K, Torigoe T, Onozuka J, Numata O, Torigoe K. 2011. A bronchial cast caused by pulmonary hemorrhage due to a vitamin $\mathrm{k}$ deficiency. Pediatrics international : official journal of the Japan Pediatric Society. 53(1):133-134.

4. Pérez-Soler A. 1989. Cast bronchitis in infants and children. American journal of diseases of children (1960). 143(9):1024-1029.

5. Soyer T, Yalcin Ş, Emiralioğlu N, Yilmaz EA, Soyer O, Orhan D, Doğru D, Sekerel BE, Tanyel FC. 2016. Use of serial rigid bronchoscopy in the treatment of plastic bronchitis in children. Journal of pediatric surgery. 51(10):1640-1643.

6. Werkhaven J, Holinger LD. 1987. Bronchial casts in children. The Annals of otology, rhinology, and laryngology. 96(1 Pt 1):86-92.

7. Hasan RA, Black C, Reddy R. 2012. Plastic bronchitis in children. Fetal and pediatric pathology. $31(2): 87-93$. 
8. Singhi AK, Vinoth B, Kuruvilla S, Sivakumar K. 2015. Plastic bronchitis. Annals of pediatric cardiology. $8(3): 246-248$.

9. Yuan L, Huang JJ, Zhu QG, Li MZ, Zhuo ZQ. 2020. Plastic bronchitis associated with adenovirus serotype 7 in children. BMC pediatrics. 20(1):268.

10. Annangi S, Smith KH. 2020. Bloody bronchial cast-aftermath of hemoptysis. American journal of respiratory and critical care medicine. 201(2):243-244.

11. Coonar A. 2005. Blood clot cast of the bronchial tree. European journal of cardio-thoracic surgery : official journal of the European Association for Cardio-thoracic Surgery. 28(3):490.

12. Okada Y, Okada A, Narumiya H, Iiduka R, Katsura K. 2017. Bloody bronchial cast formation due to alveolar hemorrhage associated with h1n1 influenza infection. Internal medicine (Tokyo, Japan). 56(20):27472751.

13. Korlacki W, Korecka K, Dzielicki J. 2011. Foreign body aspiration in children: Diagnostic and therapeutic role of bronchoscopy. Pediatric surgery international. 27(8):833-837.

Legends

Figure 1. A/B, CT scan of the patient's chest, showing blockage of the left bronchus and its branches (black arrows).

Figure 2. Blood clot cast of the left bronchial tree.

Figure 3.A/B, CT scan performed on the fourth day after cast removal, showing that the trachea and bronchi were unobstructed. 


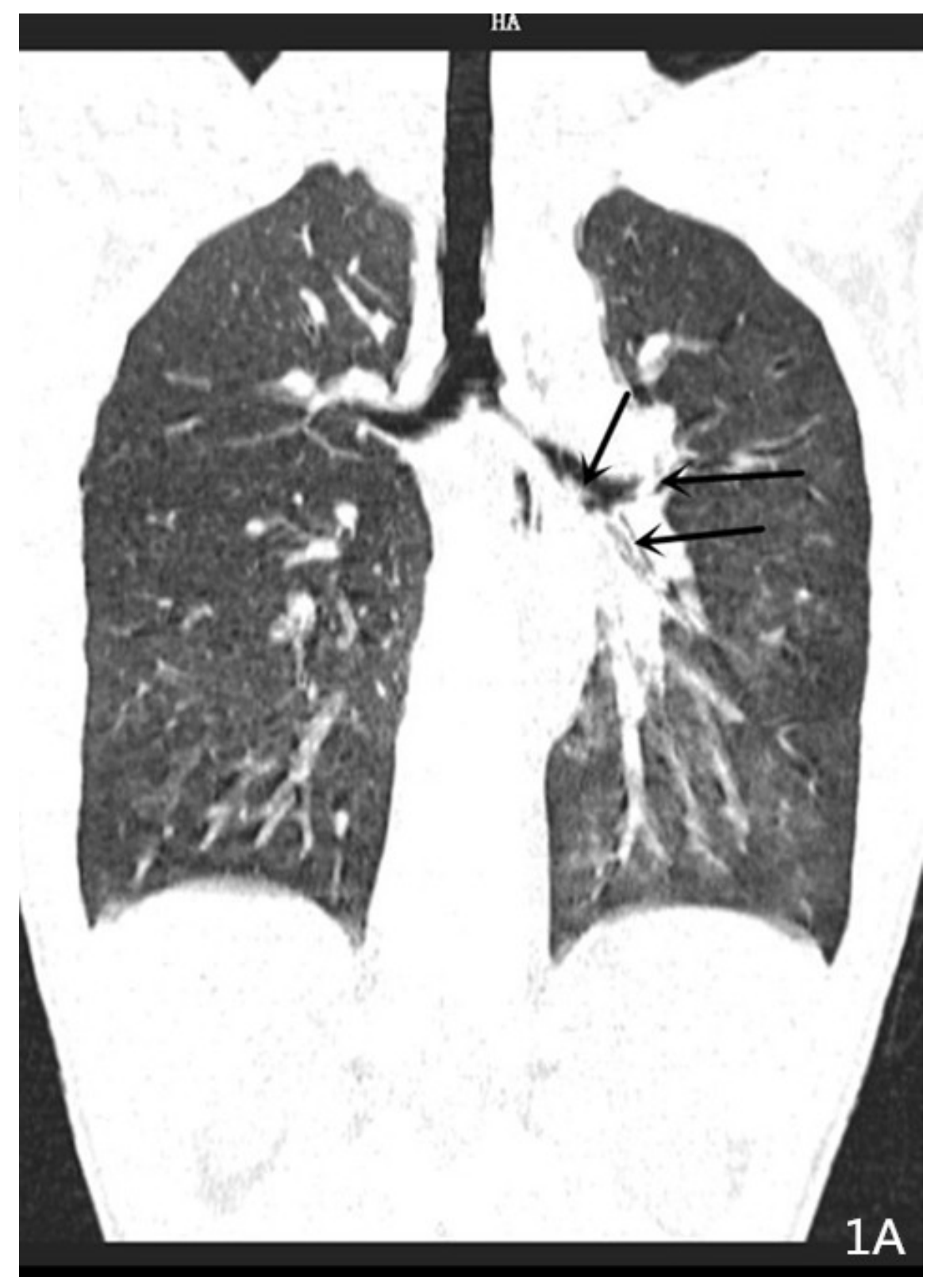




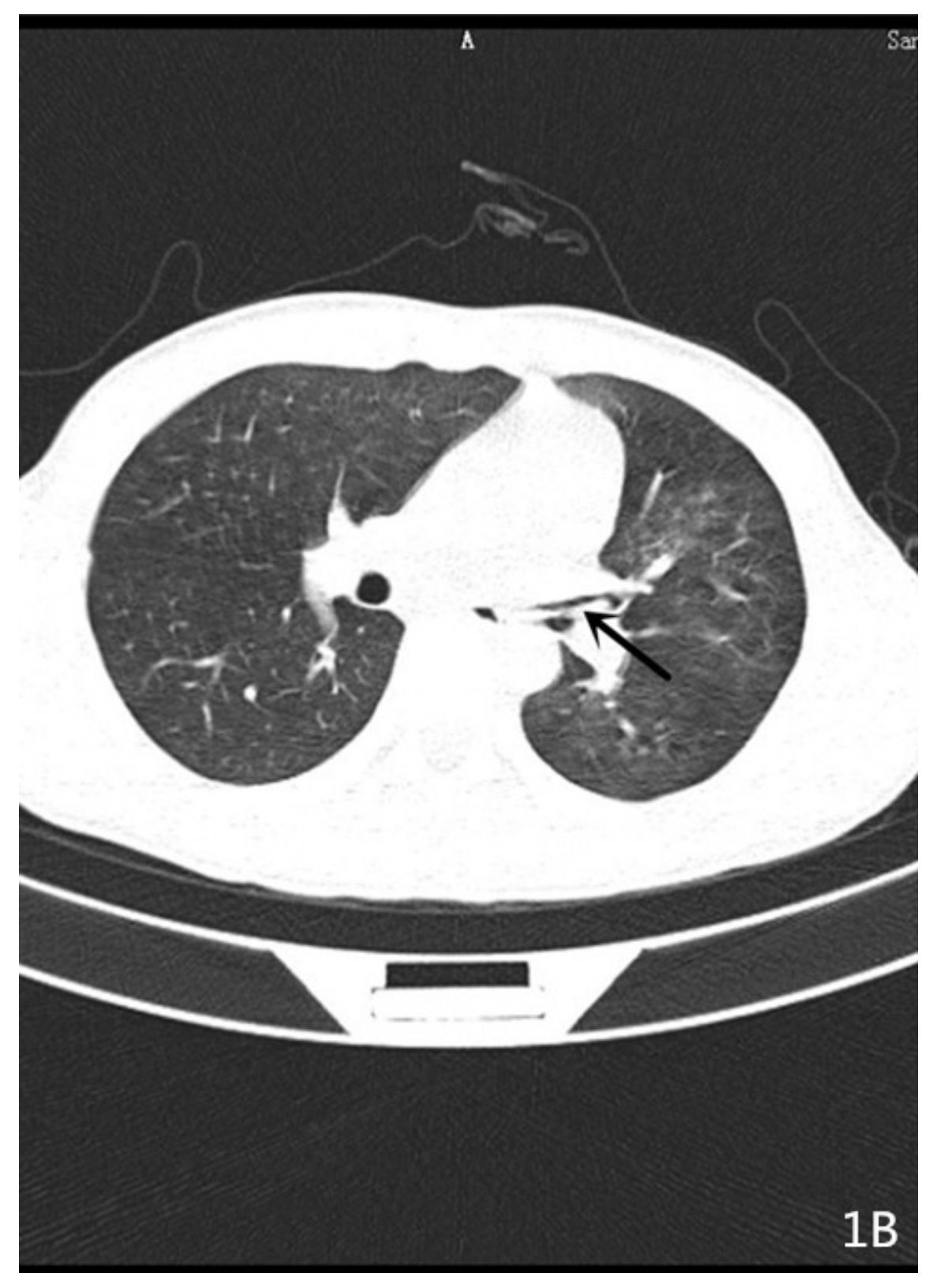




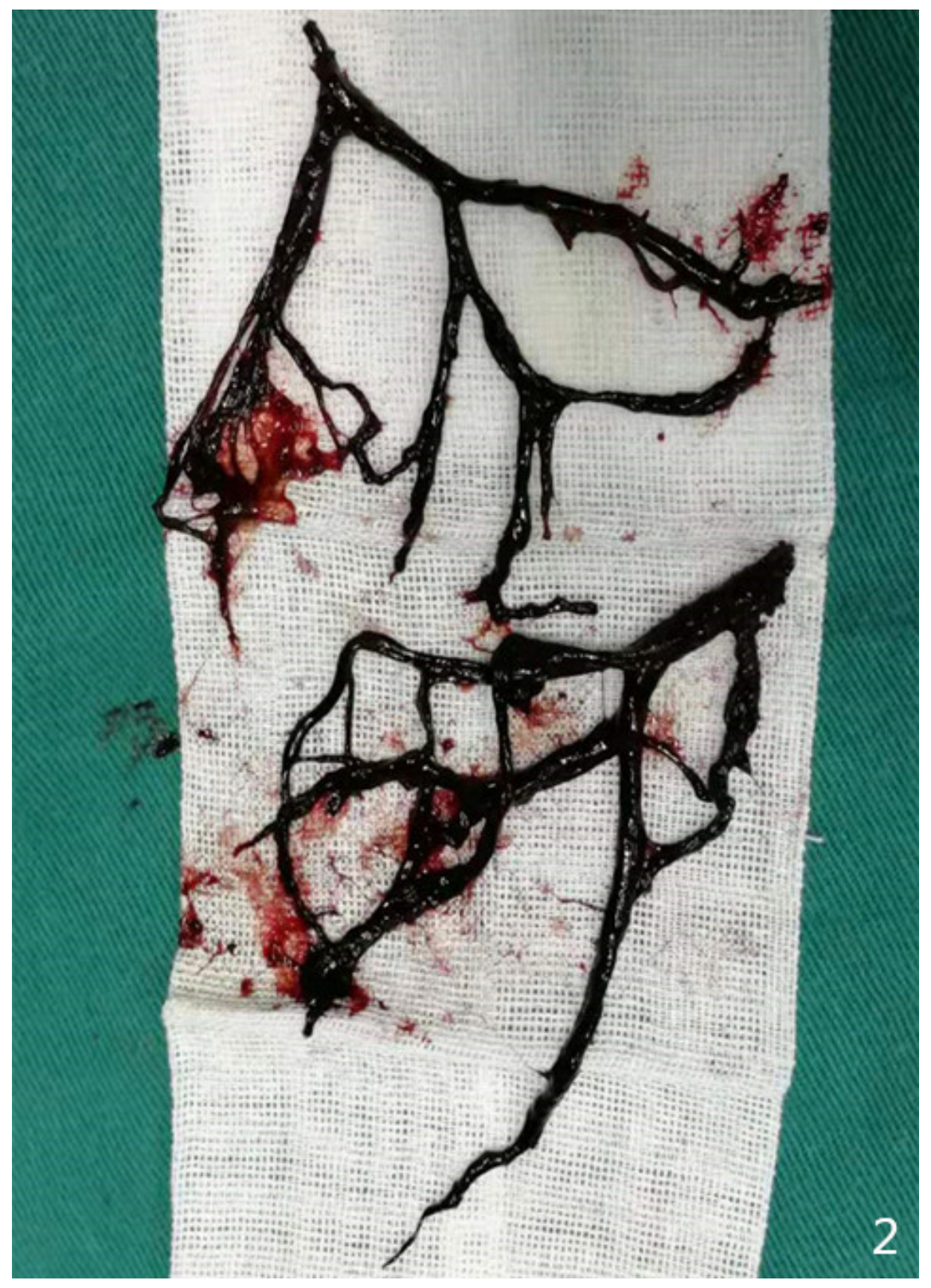




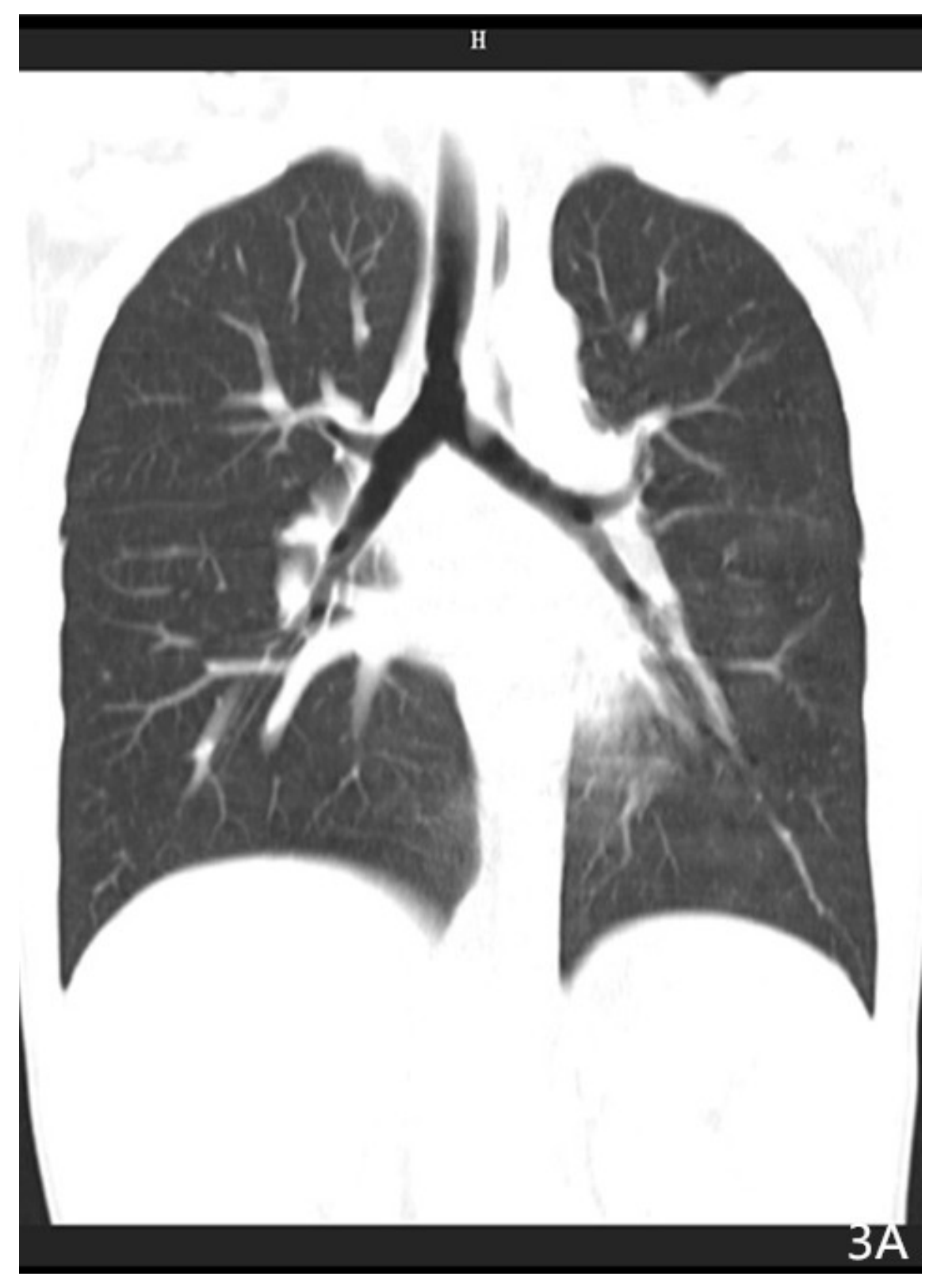




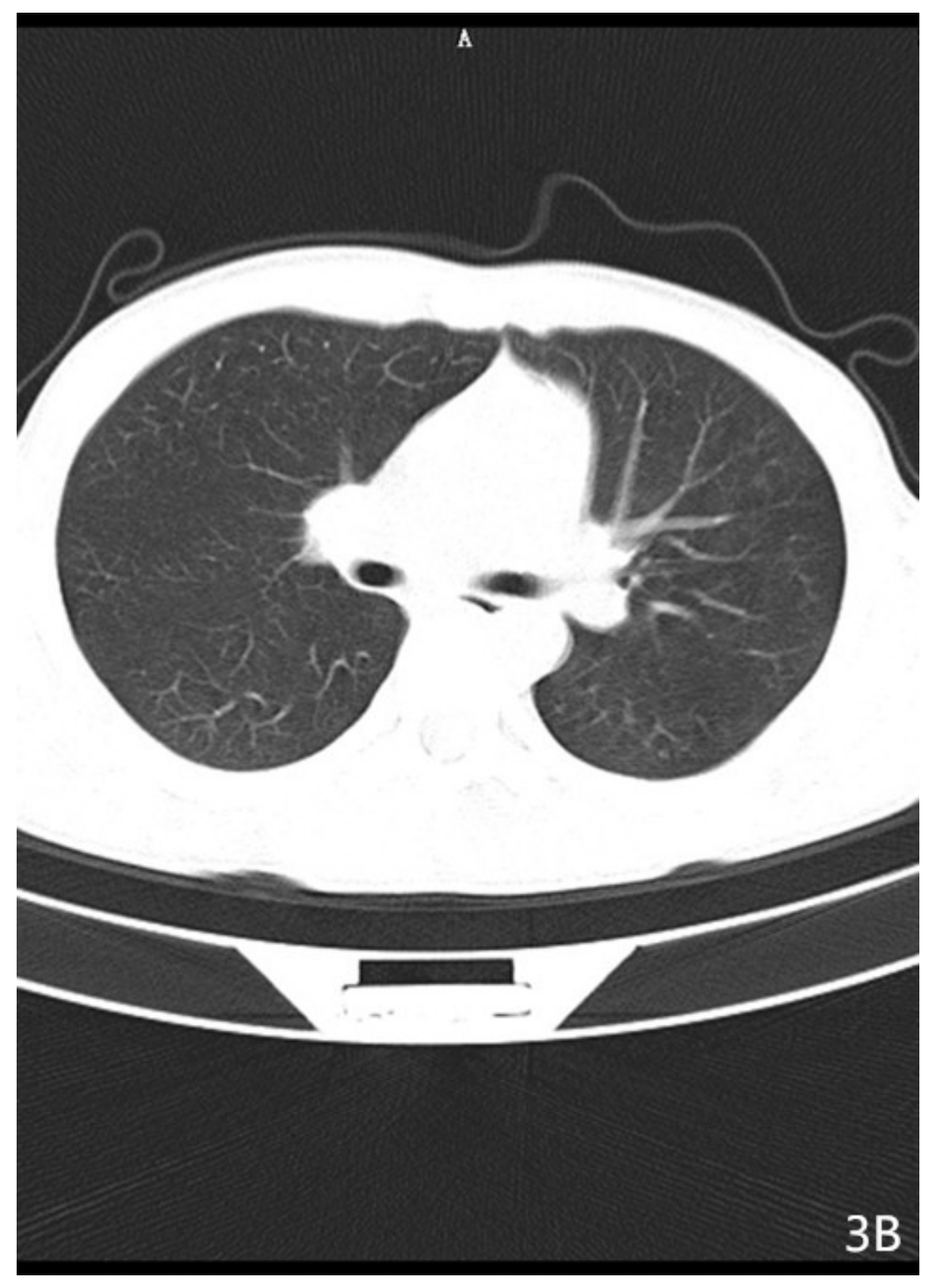




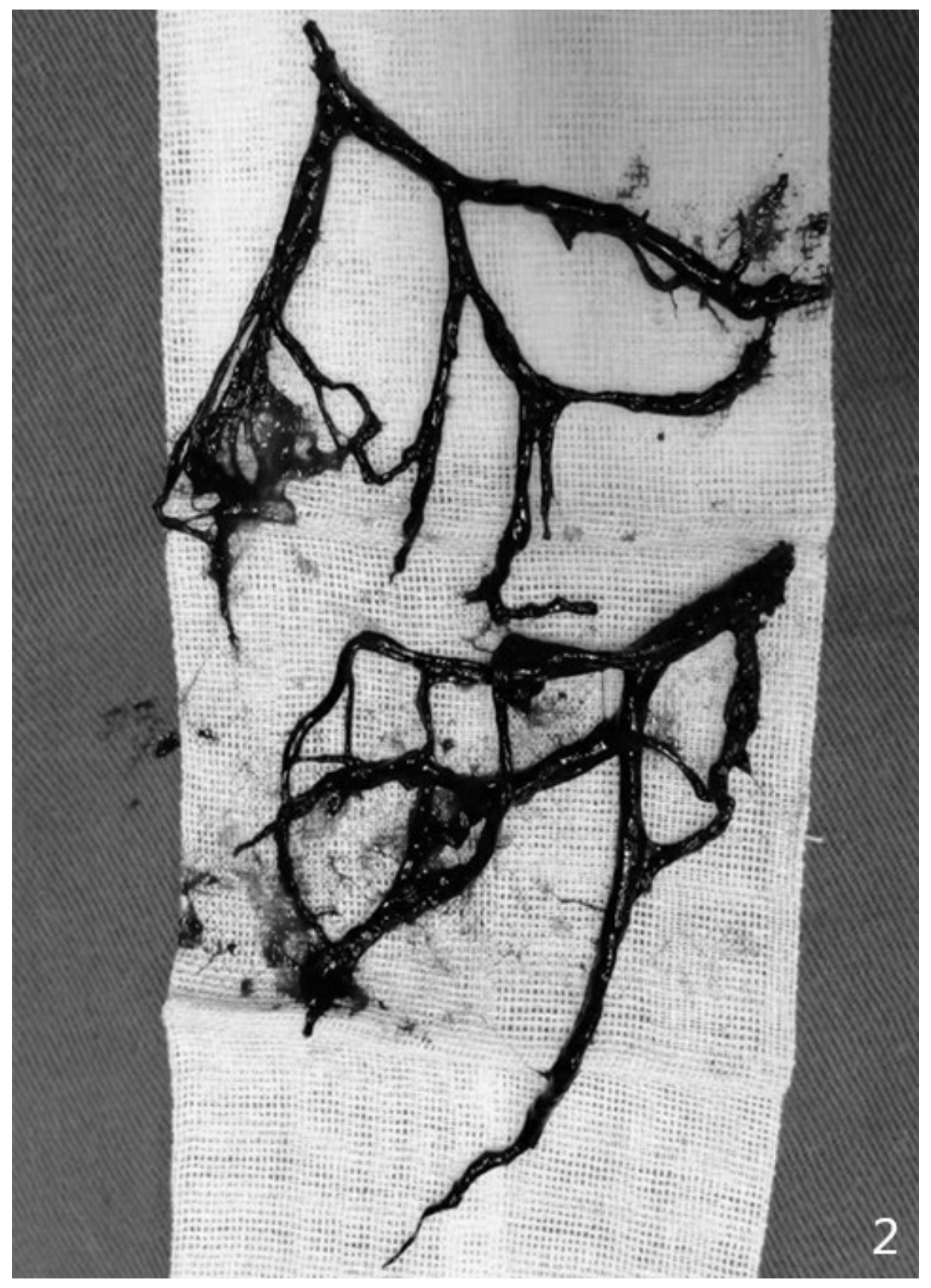

